\title{
Loop Diuretic
}

National Cancer Institute

\section{Source}

National Cancer Institute. Loop Diuretic. NCI Thesaurus. Code C49184.

Any agent belong ing to the class of loop diuretics. Loop diuretics block and inhibit the function of the sodium-potassium-chloride $(\mathrm{Na}+, \mathrm{K}+, \mathrm{Cl}-)$ cotransporter system in the thick ascending limb of the loop of Henle, thereby inhibiting the reabsorption of sodium, potassium, and chloride ions. This leads to an increase in the excretion of sodium, potassium, chloride, calcium, magnesium, ammonium and water. 